\title{
Rate of Wage Levelling or Diversification of OECD Member Countries: In Which Countries Are Wage More Inequality?
}

\author{
Diana BÍLKOVÁ
}

University of Economics, Prague, Czechia; bilkova@vse.cz

\begin{abstract}
The main objective of this research is to capture wage inequality in OECD member countries and to find out in which countries wages are the most levelled and in which countries wages are the most diversified. The Gini coefficient and index were used for this purpose. The highest values of the Gini index were found in two Latin American OECD member countries, namely in Chile and Mexico, values exceeding 45 percent indicate strong wage diversification. On the contrary, Slovenia, Slovakia, the Czechia show a strong levelling of wages, the values of the Gini index are around 25 percent. The data for this research come from the official OECD statistical database and International Labour Organization Database (ILOSTAT). Gross annual wage after its conversion to purchasing power parity (PPP) in 2018 constant prices at USD is the main research variable. The data for this research includes employees in both business and non-business spheres. The wage is paid to the employee for the work done in the private (business) sphere, salary in the budget (state, public, non-business) sector.
\end{abstract}

Keywords: wage levelling; wage diversification; wage inequality; Gini coefficient of diversification; Gini index of diversification; Lorenz curve of diversification

\section{JEL Classification: D31; J31; E24}

\section{Introduction}

In the developed countries of the world, wage shears are constantly opening up. Wages and salaries of employees with the highest incomes are rising the most. For example, wage differences are evidenced by the difference between the average wage and the median wage, too. Most employees in the developed countries in the world do not reach the average wage. Real wages of experts are currently rising in the developed countries of the world, so it can be expected that this disparity will continue to increase.

Rising wage and income inequality is also a major problem in Organization for Economic Cooperation and Development (OECD) countries, especially in view of the recent coronary crisis and the fact that the prospects for a slowdown in this growth is currently very low, especially for more developed countries. In this context, many researchers, and scholarly articles around the world are published on topic of wage and income diversifications and inequality.

Marjit, Beladi, and Chakrabarti (2004) provide a theoretical analysis of the possible impact of trade and fragmentation on the skilled-unskilled wage gap in a small developing 
economy. In particular, they illustrate the possibility of a decline in the relative wage of the unskilled labour following an improvement in the terms of trade. Analysing data from the Current Population Survey for 1963 to 2005, Autor, Katz and Kearney (2008) find that the slowing of the growth of wage inequality in the 1990s hides a divergence in the paths of upper-tail (quantiles 90/50) inequality, which has increased steadily since 1980, even adjusting for changes in labour force composition, and lower-tail (quantiles 50/10) inequality, which rose sharply in the first half of the 1980s and plateaued or contracted thereafter. Fluctuations in the real minimum wage are not a plausible explanation for these trends since the bulk of inequality growth occurs above the median of the wage distribution. Western and Rosenfeld (2011) observe that from 1973 to 2007, private sector union membership in the United States declined from 34 to 8 percent for men and from 16 to 6 percent for women. During this period, inequality in hourly wages increased by over 40 percent. The authors report a decomposition, relating rising inequality to the union wage distribution's shrinking weight and they argue that unions helped institutionalize norms of equity, reducing the dispersion of nonunion wages in highly unionized regions and industries. Acosta and Gasparini (2007) present evidence of the hypothesis that capital accumulation can modify the relative productivity between skilled and unskilled workers, leading to changes in the wage structure, taking advantage of the variability in wage premia and capital investment across industries in Argentina's manufacturing sector. The authors conclude that the wage premium for skilled workers increased more in those industries with higher investment in machinery and equipment.

This paper deals with the analysis of the development of wage diversification in OECD member countries in the period just after the global economic crisis, specifically 2013-2018. The main aim of the current research is to quantify the development of wage diversification using the Gini diversification coefficient and then the Gini diversification index with the intention of comparing this development in individual countries or their groups. The following scientific hypotheses follow from the set research objectives:

H1: In all OECD member countries, the wage diversification expressed by the Gini index does not exceed 50 percent.

$\mathrm{H} 2$ : Wage diversification in post-communist countries is lower than in other countries due to the past almost egalitarian system.

H3: Central and South American OECD countries show the highest degree of wage diversification within OECD member countries.

H4: Non-European OECD member countries are characterized by a higher degree of wage diversification than European countries.

\section{Database}

The data for this research come from the official OECD statistical database and International Labour Organization Database (ILOSTAT). Gross annual wage after its conversion to purchasing power parity (PPP) in 2018 constant prices at USD is the main research variable. Then, average gross annual wage after its conversion to PPP in 2018 constant prices at USD is the main research wage indicator - hereinafter in the text referred 
to as average wage. All 36 OECD member countries are statistical units of research. These states are divided into seven blocks according to their geographical location, historical development, culture, social systems, and level of advancement of the country, see Table 1.

Table 1. Country blocks of the OECD member states, country names and their international codes.

Source: www.mvcr.cz

\begin{tabular}{|c|c|c|c|c|c|}
\hline Group of countries & Country & Code & Group of countries & Country & Code \\
\hline \multirow{7}{*}{$\begin{array}{l}\text { Western European } \\
\text { developed countries }\end{array}$} & Austria & AUT & \multirow{5}{*}{$\begin{array}{l}\text { Central European } \\
\text { post-communist } \\
\text { countries }\end{array}$} & Czechia & CZE \\
\hline & Belgium & BEL & & Hungary & HUN \\
\hline & France & FRA & & Poland & POL \\
\hline & Germany & DEU & & Slovakia & SVK \\
\hline & Luxembourg & LUX & & Slovenia & SVN \\
\hline & Netherlands & NLD & \multirow[t]{3}{*}{ Baltic countries } & Estonia & EST \\
\hline & Switzerland & $\mathrm{CHE}$ & & Latvia & LVA \\
\hline \multirow[t]{5}{*}{ Scandinavian countries } & Denmark & DNK & & Lithuania & LTU \\
\hline & Finland & FIN & \multirow{10}{*}{$\begin{array}{l}\text { Non-European } \\
\text { countries }\end{array}$} & Australia & AUS \\
\hline & Iceland & ISL & & Canada & CAN \\
\hline & Norway & NOR & & Chile & $\mathrm{CHL}$ \\
\hline & Sweden & SWE & & Israel & ISR \\
\hline \multirow[t]{2}{*}{ Anglo-Saxon countries } & Ireland & IRL & & Japan & JPN \\
\hline & United Kingdom & GBR & & Mexico & MEX \\
\hline \multirow{4}{*}{$\begin{array}{l}\text { South European } \\
\text { countries }\end{array}$} & Greece & GRC & & New Zealand & NZL \\
\hline & Italy & ITA & & South Korea & KOR \\
\hline & Portugal & PRT & & Turkey & TUR \\
\hline & Spain & ESP & & United States & USA \\
\hline
\end{tabular}

The data for this research includes employees in both business and non-business spheres. The wage is paid to the employee for the work done in the private (business) sphere, salary in the budget (state, public, non-business) sector. From the point of view of the analysed data from the OECD statistical database, both wages in the business sphere and salaries in the non-business sector are included under the wage term.

The data was processed using the SAS, SPSS and Statgraphics statistical packets and the Microsoft Excel spreadsheet.

\section{Theory and Methodology}

Gini coefficient is related to the popular Lorenz curve, see Figure 1. In this figure, the Lorenz curve represents the arc indicated by the arrow. The two extreme Lorenz curve shape options for full levelling and full diversification are shown here, too.

Lorenz curve is plotted in a rectangular chart with two scales from zero percent to a hundred percent. The cumulative relative frequencies (in percentages) of the statistical units that carry the variable of interest are on the horizontal axis. On the contrary, the cumulative totals (in percentages) of the concentrated variable are on the vertical axis. Thus, the coordinates of the points on the Lorenz curve are the cumulative relative frequencies (in percentages) of the statistical units that carry the variable under consideration, and the corresponding cumulative totals (in percentages) of the concentrated variable. In the case of full levelling, the Lorenz curve coincides with the indicated diagonal of the square, which 
means that each statistical unit obtains the equal part from the total sum of the values of the researched variable. The more the Lorenz curve bends, the greater is the diversification of the variable under investigation, i.e. the concentration of a relatively large part of the total sum of the values of the monitored variable into a small number of statistical units. In the case of full diversification, the Lorenz curve turns into two each other perpendicular lines, i.e. it merges with the horizontal axis and the right edge of the graph. This means that the total sum of the values of the variable being examined is concentrated into only one statistical unit.

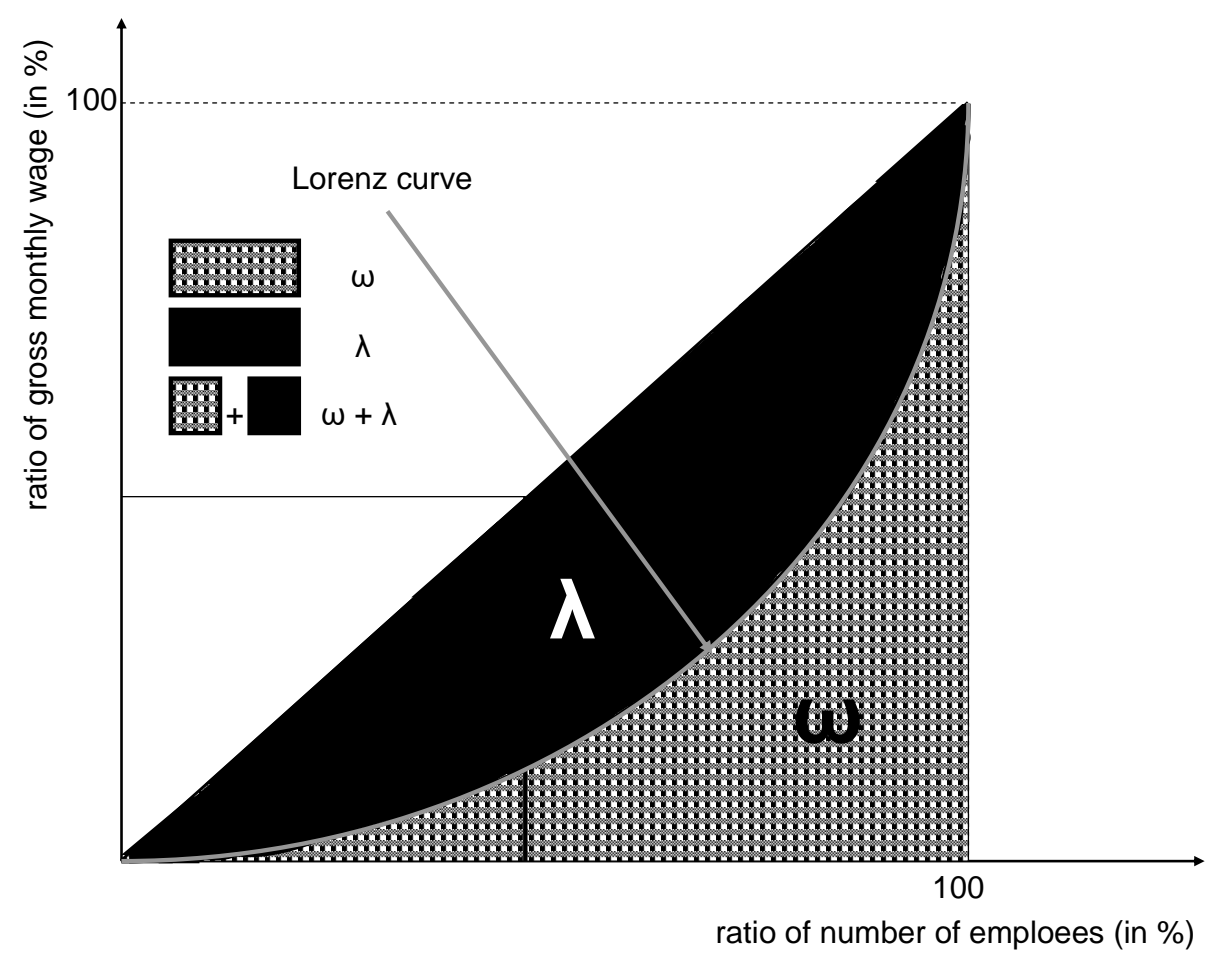

Figure 1. Lorenz curve

The characteristic of diversification is then the ratio of the area content between the square diagonal and the Lorenz curve to the area content of the whole triangle below the diagonal of the square. This characteristic is called the Gini coefficient of diversification

$$
G C=\frac{\lambda}{\lambda+\omega} .
$$

The Gini coefficient takes values in the range from zero to one, where it gets value zero at extreme levelling, when each statistical unit obtains the equal part from the total sum of the values of the researched variable, and it gets value one at extreme differentiation, when the total sum of the values of the variable being examined is concentrated into only one statistical unit. The Gini coefficient is considered to be one of the most suitable indicators of measuring wage and income inequalities. The Gini coefficient multiplied by a hundred is called the Gini index. This is the same statistic, expressed only as a percentage.

We calculate the Gini coefficient from the interval frequency distribution as 


$$
G C=\frac{\left.\hat{l}_{i=1}^{l}\left[M_{i}(h)-M_{i}(d)\right] \times k\left(p_{i}\right) \rtimes 1-k\left(p_{i}\right)\right]}{\left.\prod_{i=1}^{l}\left[M_{i}(h)-M_{i}(d)\right] \rtimes 1-k\left(p_{i}\right)\right]},
$$

where: $M_{i}(h)$ is upper limit of the $i^{\text {th }}$ interval, $i=1,2, \ldots, l$,

$M_{i}(d)$ is lower limit of the $i^{\text {th }}$ interval, $i=1,2, \ldots, l$,

$p_{i}$ is relative frequency in the $i^{\text {th }}$ interval, $i=1,2, \ldots, l$,

$k\left(p_{i}\right)$ is cumulative relative frequency in up to the $i^{\text {th }}$ interval, $i=1,2, \ldots, l$,

$l$ is number of intervals,

or, if we know the averages at each interval, using the formula

$$
G C=\frac{\left.i_{i=1}^{l}\left[\bar{M}_{i+1}-\bar{M}_{i}\right] \ngtr k\left(p_{i}\right) \rtimes 1-k\left(p_{i}\right)\right]}{\bar{M}},
$$

where: $\quad \bar{M}_{i+1^{-}} \bar{M}_{i}$ is the difference of the $i+1$-th and $i^{\text {th }}$ interval averages, $i=1,2, \ldots, l$,

$\bar{M}$ is the total average over all intervals,

$p_{i}$ is relative frequency in the $i^{\text {th }}$ interval, $i=1,2, \ldots, l$,

$k\left(p_{i}\right)$ is cumulative relative frequency in up to the $i^{\text {th }}$ interval, $i=1,2, \ldots, l$,

$l$ is number of intervals.

Gini coefficient can be also calculated using the mathematical formula as an average of differences in wages between all possible pairs of individuals

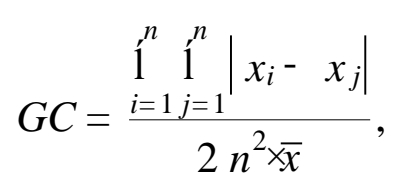

where: $x_{i}, x_{j}$ are wages of two randomly chosen individuals, $i, j=1,2, \ldots, n$,

$n$ is number of individuals,

$\bar{x}$ is an average.

The advantage of this calculation procedure is that it is not necessary to sort individuals or groups according to monitored variable. However, the so-called Brownian formula is more often used to calculate the Gini coefficient

$$
G C=\left|1-1_{i=1}^{n}\left(x_{i}-x_{i-1}\right) \rtimes\left(y_{i}+y_{i-1}\right)\right|,
$$

where: $x_{i}$ is the cumulative ratio of beneficaries of monitored variable, $i=1,2, \ldots, n$, $y_{i}$ is the cumulative ratio of monitored variable, $i=1,2, \ldots, n$. 


\section{Results}

Figures 2-6 quantify the development of diversification of OECD member countries in the period 2013-2018. Specifically, Figure 2 refers to Western European developed countries, Figure 3 represents Scandinavian countries, Figure 4 represents Anglo-Saxon and South European countries (too small blocs of countries from Table 1 were plotted with another small bloc), Figure 5 refers to Central European post-communist and Baltic post-communist countries, and finally Figure 6 includes Non-European countries.



Figure 2. Gini index (in \%) of wage of Western European developed countries

The Gini index takes values in the range from zero to one hundred, where it gets value zero at extreme levelling, when all employees have the same wage, and it gets value one hundred at extreme differentiation, when all wage belongs to one employee. The closer the Gini index is to one hundred, the higher inequality is in wage distribution. The closer the Gini index is to zero, the higher levelling is in wage distribution. 


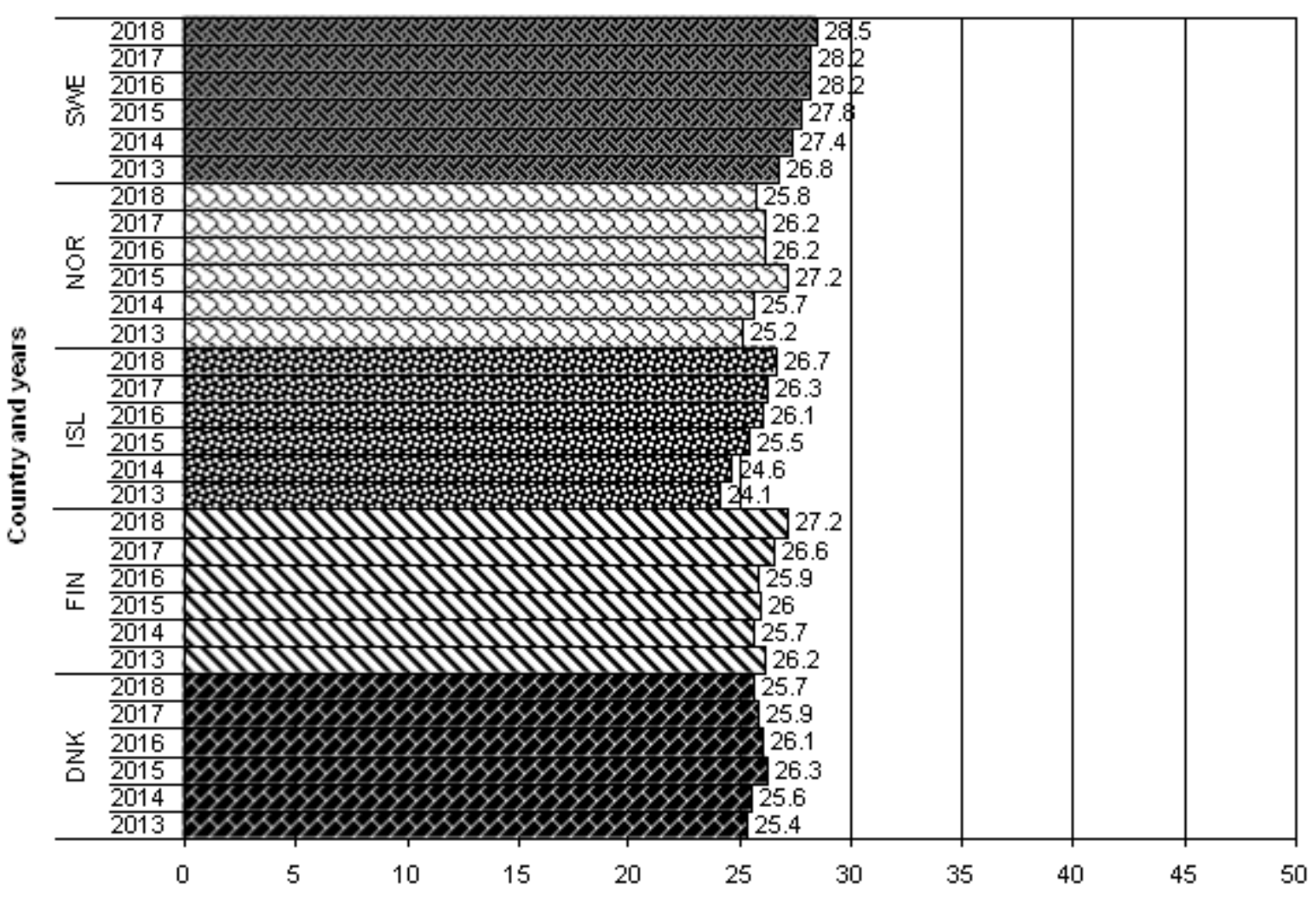

Figure 3. Gini index (in \%) of wage of Scandinavian countries

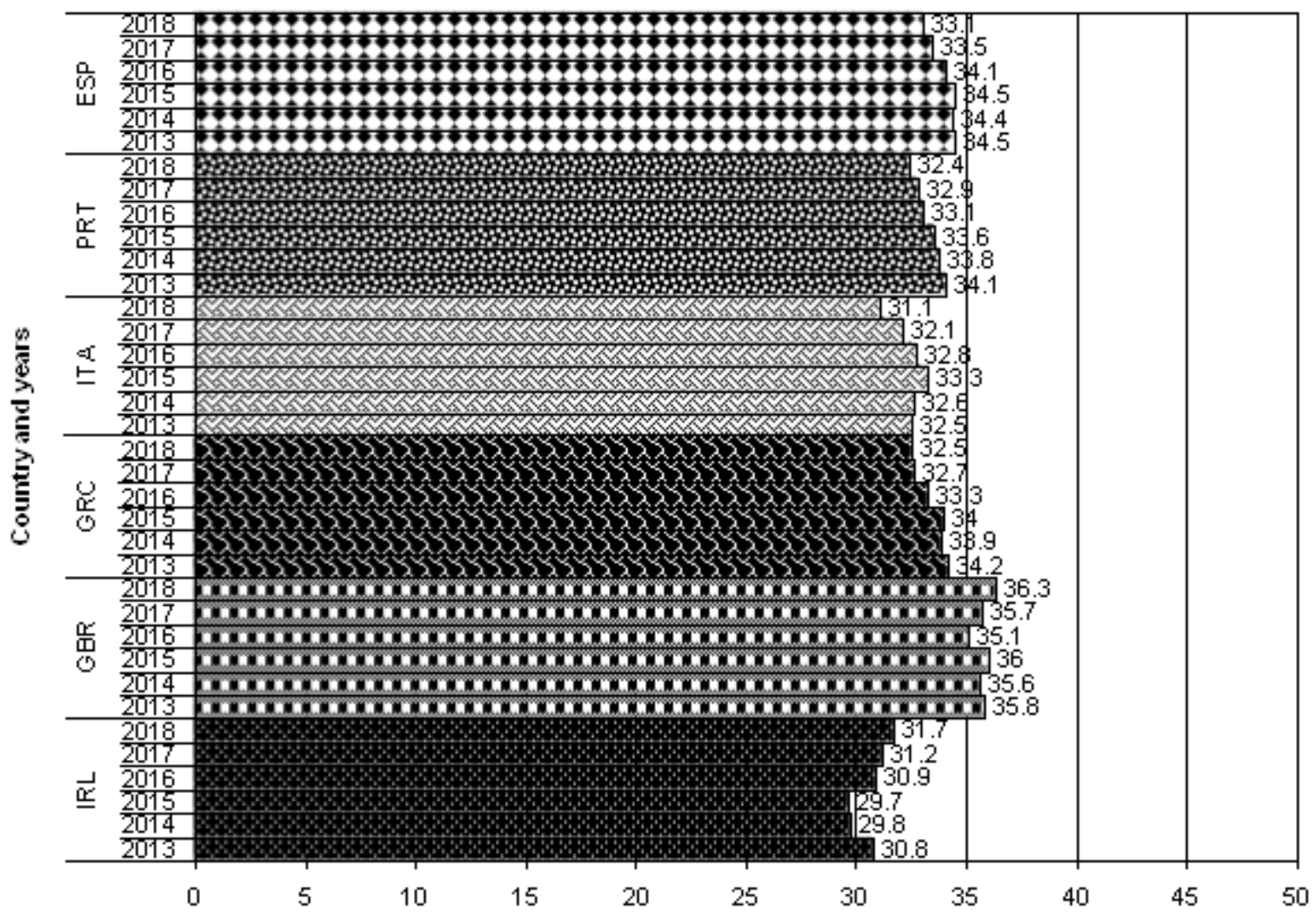

Figure 4. Gini index (in \%) of wage of Anglo-Saxon and South European countries 




Figure 5. Gini index (in \%) of wage of Central European post-communist and Baltic post-communist countries

Figures 2-6 show that the highest values of the Gini index were found in two Latin American OECD member countries, namely in Chile and Mexico, with values in excess 45 percent indicating strong wage diversification. Chile and Mexico are the only Latin American countries to be members of the OECD. Low taxes are typical for both countries. Employers' wage costs in both countries are the lowest among OECD member countries. When comparing average net wages, the differences between Western European countries and the two Latin American countries are much lower than when comparing gross wages.

On the contrary, post-communist countries, namely Slovenia, Slovakia, and the Czechia, show the lowest wage diversification, which does not exceed 27 percent. As the people of post-communist countries switched from the original egalitarian systems to capitalism from the early 1990s, they encountered a new phenomenon, such as the rise of social inequality. The original Yugoslavia had a looser regime even before the collapse of the communist bloc, which also affected the economy, and since some time it was even possible to do business freely. The Slovenian economy benefits from its advantageous location, which in a small 
state connects the eastern part of the Alps, which is important for tourists in all seasons, several tens of meters long coast of Adriatic Sea and it is a transit country for travel to the Balkans, especially to neighbouring Croatia. The country has a high level of banking, a very good infrastructure, a dense and high-quality motorway and road network and high-quality tourist centers.

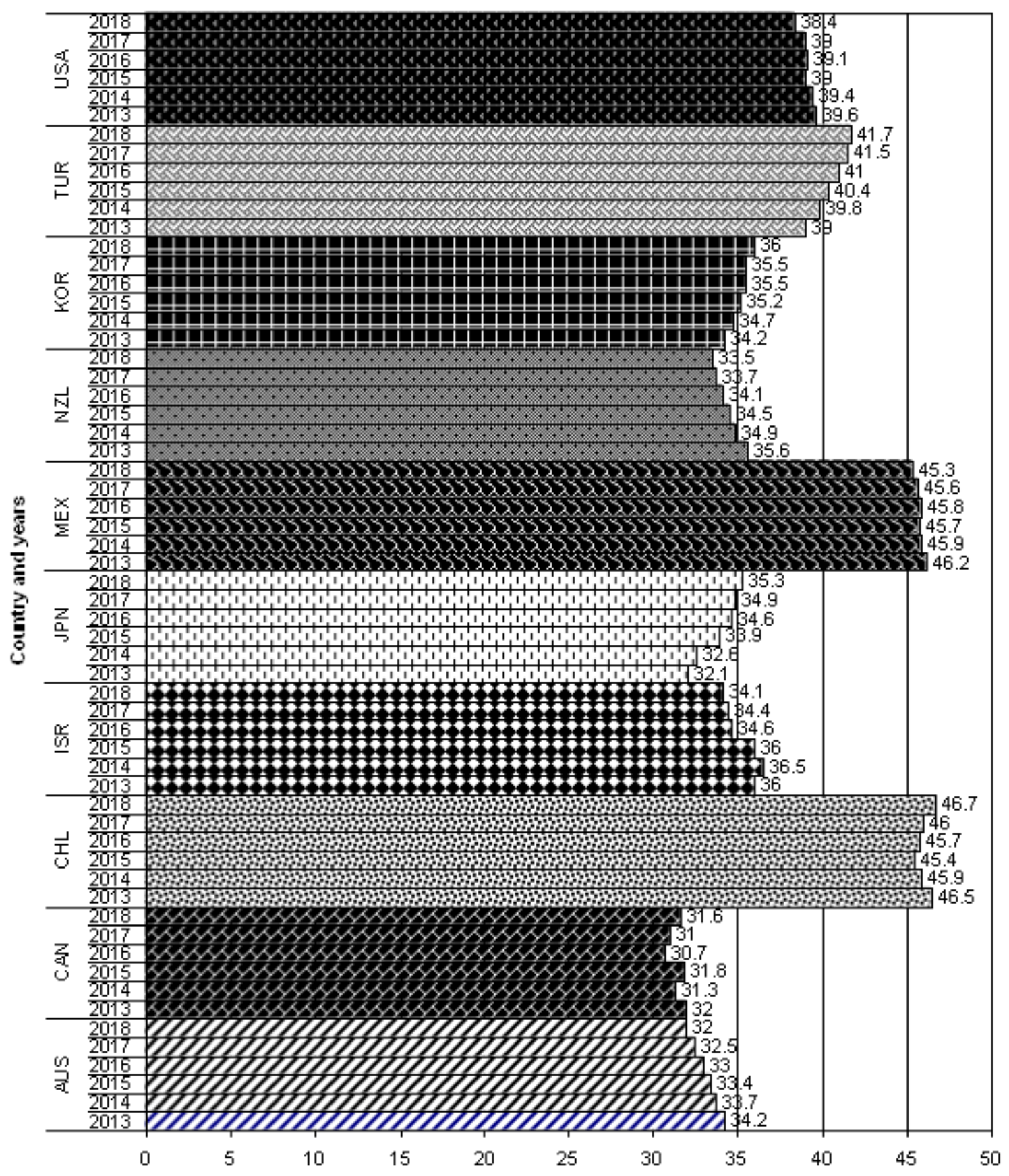

Figure 6. Gini index (in \%) of wage of Non-European countries.

When independent Czechia and Slovakia emerged from the original Czechoslovakia on the 1st January 1993, these were countries in which the process of economic transformation was already underway. Both countries were affected by an unsuitable and completely unsustainable structure of industry, focused mainly on heavy industry, with Slovakia 
accounting for about 30 percent and the Czechia for about 70 percent of the industrial production of the entire federation. In Slovakia, however, in the first years of independence, reforms slowed down and mainly corruption appeared. However, at the beginning of the third millennium, some economic reforms, which triggered very sharp GDP growth and falling unemployment, were sharply criticized by the left parties, especially for lower living standards, mostly poorer. Slovakia is the third strongest economy of the post-communist countries after the Czech Republic and Slovenia. The Czechia has the most stable and prosperous economy of all the countries of the former Council of Mutual Economic Assistance (CMEA). The basis of the Czech economy is industry and services, agriculture and other primary production are underrepresented. The Czechia has the largest number of self-employed persons per capita in Europe. Unemployment and government debt in the Czech Republic remain among the lowest in Europe.

Overall, it can be stated that wage diversification is higher in non-European countries rather than in European countries. From European countries, the United Kingdom shows a relatively large wage diversification, which does not fall below 35 percent throughout the period under review. All four southern European countries also show a relatively high degree of wage diversification, which does not fall below 31 percent over the entire period. On the contrary, all Central European post-communist countries are characterized by low wage diversification not exceeding 30 percent in any of these countries throughout the period under review, only Poland approached 30 percent in the period immediately after the global economic crisis. The situation is different in the post-communist Baltic countries, where we record relatively strong wage diversification, especially in Lithuania, where it has reached almost 39 percent in the last years of the period under review. All Scandinavian countries and all Western European developed countries are characterized by relatively low wage diversification, which does not exceed 31 percent in any country throughout the research period.

\section{Conclusions}

According to the results obtained, Slovenia, Slovakia and the Czechia show the lowest wage diversification of all OECD member countries. For example, in the Czechia, when comparing one-fifth of the highest-paid employees and one-fifth of the lowest-paid employees, this group of the richest has about 3.5 times more than the group of the poorest. There are several reasons why wages are so balanced in these countries. One of them is the historical heritage from the communist era, when in a non-free environment, the wages of employees were limited and distorted. However, this would not be enough for the first place in the ranking, because other countries have communist experience, too. One of the reasons why wage diversification is so low in these countries is the relatively successful transformation of the economies of these countries. If we look at the opposite end of the scale, we see some Eastern bloc countries where the transformation of the economy after the end of communism was much wild than in the three countries.

Now, we evaluate the defined scientific hypotheses based on the obtained research results: 
H1: Proven. The two OECD member countries of Latin America show the highest wage diversification within the OECD member countries in the period 2013-2018. There are Chile and Mexico, the wage diversification expressed by the Gini index does not exceed 47 percent in either of these two countries in that period.

H2: Proven in terms of the Central European post-communist country bloc, with the exception of Poland. The Baltic post-communist countries bloc shows relatively high wage diversification, probably due to quite dramatic demographic effects.

H3: Proven, Chile and Mexico are the only two OECD member countries in Latin America to show the highest level of wage diversification within OECD member countries in 2013-2018 due to the fact that the government does not make any major interventions in the economy here. During this period, the Gini index ranged 45.4-46.7 percent in Chile and 45.3-46.2 percent in Mexico.

H4: Proven in part. Wage diversification in non-European OECD member countries is in the range of 30.7-46.7 percent, which is completely outside the wage diversification of the Scandinavian countries, the Central European post-communist and essentially Western European developed countries. However, the wage diversification of non-European OECD member countries partly overlaps with the Anglo-Saxon countries, the Southern European countries and the Baltic post-communist countries.

In OECD member countries, the average wage increased even during the economic crisis, although the wage demands of many jobseekers decreased, mainly to have a job. Employees performing ancillary work in particular had a difficult situation on the labour market, while the wages of professionals who are key for employers, have risen in recent years. In all developed OECD countries, therefore, the best investment for citizens is spending on education and increasing their own know-how. Professionals in all fields have the best starting position on the labour market. Which is why lifelong learning is a way to secure not only an average and higher wage, but also the easiest way to find a suitable job.

The direct relationship between employees' wages and their purchasing power supports monitoring not only the level of wages, their structure, but also examining the development of wage diversification while monitoring sales opportunities for long-term and short-term consumer products. Therefore, the distribution of employees' wages should be also taken into account by entrepreneurs when considering their sale areas. The estimation of wage distributions based on data on their diversification makes possible to determine approximately the total volume of wage resources in various enterprises. Knowledge of the distribution of employees' wages accompanied by data on their diversification should be also taken into account by politicians at various steps within the state budget, such as at various considerations regarding the level of the tax burden.

In the following research, it is possible to focus on estimates of the future development of wage distributions, which would enable to combine considerations of wage diversification with socio-political considerations, for which it is usually not enough to estimate future wage level developments, but to estimate the future shares of low, medium and high wages, too. 
Acknowledgments: This paper was subsidized by the funds of institutional support of a long-term conceptual advancement of science and research number IP400040 at the Faculty of Informatics and Statistics, University of Economics, Prague, Czech Republic.

\section{References}

Acosta, P., \& Gasparini, L. (2007). Capital Accumulation, Trade Liberalization, and Rising Wage Inequality: The Case of Argentina. Economic Development and Cultural Change, 55(4), 793-812. https://doi.org/10.1086/516764 Autor, D. H., Katz, L. F., \& Kearney, M. S. (2008). Trends in U.S. Wage Inequality: Revising the Revisionists.

The Review of Economics and Statistics, 90(2), 300-323. https://doi.org/10.1162/rest.90.2.300

Marjit, S., Beladi, H., \& Chakrabarti, A. (2004). Trade and Wage Inequality in Developing Countries. Economic Inquiry, 42(2), 295-303. https://doi.org/10.1093/ei/cbh061

Western, B., \& Rosenfeld, J. (2011). Unions, Norms, and the Rise in U.S. Wage Inequality. American Sociological Review, 76(4), 513-537. https://doi.org/10.1177/0003122411414817 